\title{
Álcool Combustível no Brasil e Path Dependence ${ }^{1}$
}

\author{
Pery Francisco Assis Shikida² e Bruno Benzaquen Perosa ${ }^{3}$
}

Resumo: Este trabalho tem como objetivo analisar a relação de path dependence no sistema econômico e institucional do álcool combustível no Brasil. O etanol, após fases de crescimento e desafios, tornou-se parte da matriz energética brasileira. Esta trajetória reflete a persistência de uma rota (caminho) traçada sob influência de organizações (usinas e destilarias, setor de máquinas e equipamentos, indústria automobilística, Estado, organizações corporativistas, P\&D) e de agentes econômicos (consumidores) voltados, direta ou indiretamente, para a manutenção dessa rota escolhida. Este arranjo de "interesses" deu sustentação ao etanol brasileiro, mesmo em momentos em que a competitividade deste combustível era questionada como opção energética mais adequada para a substituição de gasolina/ diesel. Mesmo após a retomada do setor nos anos 2000, em que a tecnologia flex e as crescentes preocupações acerca das mudanças climáticas impulsionaram o setor no Brasil e no mundo, a escolha do etanol como substituto dos derivados do petróleo ainda se mostra ameaçada por novas tecnologias renováveis e mesmo pela descoberta de novas reservas de petróleo. Fica claro que, caso se deseje manter a liderança no mercado nacional de combustíveis e expandir o mercado internacional para estes produtos, a coalizão em torno do álcool combustível ainda precisará enfrentar diversas questões técnicas e institucionais.

Palavras-chaves: álcool combustível, path dependence, produção brasileira.

Abstract: This study aims to analyze the relationship of path dependence in the economic and institutional system of ethanol in Brazil. Ethanol, after stages of growth and challenges, has become part of the Brazilian energy matrix. This trajectory reflects the persistence of a path shaped under the influence of organizations (mills and distilleries, machinery and equipment sectors, automotive industry, the government, corporatist organizations, RED) and economic agents (consumers) interested, directly or indirectly, in the maintenance of the chosen route. This "interest arrangements" supported the Brazilian ethanol, even when this fuel competitiveness was questioned as the most appropriate energy option to substitute gasoline/diesel. Even after the recovery of this sector in the 2000s, when the flex-fuel technology and the GHG (Greenhouse Gases) emissions increased the ethanol

1 Os autores são gratos aos pareceristas desta revista pelos seus profícuos comentários e sugestões.

2 Pós-doutor pela FGV/SP. Professor associado da Universidade Estadual do Oeste do Paraná (Unioeste). Professor do programa de mestrado em Economia Regional da Universidade Estadual de Londrina (UEL). E-mail: peryshikida@hotmail.com.

3 Doutor em Economia pela FGV/SP. E-mail: bruno@perosa.com.br. 
demand in Brazil and abroad, the choice of ethanol as the main substitute of fossil fuels is still jeopardized by other renewable fuels and even by the discovery of new oil reserves in Brazil. In order to succeed, the collision supporting the expansion of ethanol in the international market will have to handle a myriad of technological and institutional barriers in Brazil and worldwide.

Key-words: ethanol, path dependence, Brazilian production.

Classificação JEL: Q42.

\section{Introdução}

Em 2011, o álcool combustível já representava mais de $50 \%$ do consumo de combustíveis destinados a automóveis e veículos comerciais leves movidos a álcool e/ou gasolina, exceção feita àqueles movidos a gás natural ou diesel. Esta dinâmica tem sido, em grande parte, impulsionada pela produção crescente de veículos bicombustíveis (que possibilita tanto o uso da gasolina quanto o de álcool, ou de um mix entre ambos), cuja participação no mercado de automóveis e veículos leves novos já perfaz aproximadamente 90\% [dados compilados da União da Agroindústria Canavieira de São Paulo - Unica (2011); e Associação de Produtores de Bioenergia do Estado do Paraná - Alcopar (2011)]. Atualmente, acredita-se que os automóveis bicombustíveis já representem mais de $30 \%$ da frota de automóveis leves no Brasil e este número poderá chegar a 65\% em 2012 (UNICA, 2011).

Além da tecnologia flex, outros fatores podem ser mencionados para explicar o sucesso recente do etanol no Brasil. Há questões ligadas ao contexto internacional, como a crescente preocupação ambiental e a volatilidade dos preços do petróleo nos últimos anos. Contudo, tanto a tecnologia flex quanto as questões internacionais mencionadas não explicam como este produto se firmou na matriz energética brasileira em períodos anteriores. Desde os anos 1970, o álcool figura na matriz energética brasileira e, em diversos períodos, apesar das dificuldades encontradas, esse combustível recebeu pesados incentivos governamentais, mostrando a sua importância estratégica.

Pode-se então dizer que, uma vez escolhido o álcool combustível como substituto e/ou complementar à gasolina - a partir do Decreto n. 76.593, de 14 de novembro de 1975, que criou o Proálcool (Programa Nacional do Álcool) se arquitetou um arranjo institucional para confirmar esta política, sendo seu sucesso explicado pelo corporativismo dos grupos de interesse em manter tal estratégia, o que serviu também como "barreira" para outros produtos de similar escopo.

Não obstante, o Proálcool enfrentou vários desafios, tendo sua legitimidade atacada em diversos momentos ao longo dos anos 1980 e 1990. A eficiência deste Programa sempre esteve condicionada às cotações do petróleo, sendo que, em situações de baixa, os custos de manutenção do Proálcool não pareciam se justificar. No início dos anos 1990, mesmo sob as altas cotações do petróleo devido ao conflito no Golfo Pérsico, outras forças trouxeram questionamentos à existência de políticas de proteção ao álcool de cana-de-açúcar. A onda liberal observada no início do governo Collor promoveu a desregulamentação da maioria das cadeias agroindustriais brasileiras, o que levou à extinção do IAA (Instituto do Açúcar e do Álcool) e mudou completamente a forma como o governo atuava na cadeia. Ainda assim, alguns pilares deste Programa, como a mistura de álcool anidro à gasolina, permaneceram intocáveis. A diminuição do número de automóveis a álcool nos 
anos 1990 dificultava ainda mais a manutenção desta política. Mesmo assim, as linhas mestras do Proálcool foram mantidas ao longo de todo este período, permitindo o desenvolvimento de tecnologias de produção e consumo do etanol. O desenvolvimento da tecnologia flex pode ser vista como resultado deste arranjo, tendo permitido a interação da agroindústria canavieira com a indústria automobilística na busca por esta solução tecnológica. De forma geral, a história de desenvolvimento da agroindústria canavieira no Brasil perpassa por diversas fases - da promulgação do Proálcool em 1975 até a inserção dos carros bicombustíveis em 2003, em que o desenvolvimento desse importante setor da economia brasileira foi marcado por uma forte relação de atores públicos e privados. Os novos desafios de internacionalização do etanol e sucesso de médio e longo prazo desse biocombustível como principal alternativa à gasolina colocam à prova a eficiência deste arranjo no Brasil.

Isto posto, levanta-se o seguinte questionamento: quais fatores teriam sido responsáveis pela manutenção deste arranjo institucional ao longo de todas estas fases enfrentadas pelo setor sucroalcooleiro brasileiro? Acredita-se que a existência de alguns mecanismos de rigidez tecnológica e institucional contribuiu para a manutenção da trajetória de desenvolvimento do etanol no Brasil. No campo teórico, a literatura de economia institucional tem dado atenção ao conceito path dependence, aqui entendido como herança institucional do sistema, construída via processo de aprendizado tecnológico e institucional, sendo de difícil reversibilidade, principalmente quando o padrão tecnológico se generaliza e se consolida. Mesmo tendo sido inicialmente desenvolvido para explicar trajetórias tecnológicas (DAVID, 1985), o path dependence foi estendido a processos de desenvolvimento institucional (NORTH, 1990).

Destarte, este trabalho tem como objetivo analisar a relação de path dependence no sistema econômico e institucional do álcool combustível no Brasil. A proposição deste estudo é a de que a "orquestração" de interesses, as trajetórias tecnológicas e as novas conformações institucionais pós-desregulamentação setorial configuraram o mecanismo de path dependence para este importante produto da agroindústria canavieira e da matriz energética nacional.

Este artigo contém cinco seções, incluindo esta introdução. São feitos na segunda e terceira seções, respectivamente, as exposições do referencial metodológico deste trabalho e de uma breve revisão teórica sobre o path dependence. $\mathrm{Na}$ quarta seção encontra-se a discussão central desta pesquisa, focada na análise do álcool combustível à guisa do referencial teórico proposto. Na quinta e última seção são feitas as conclusões deste artigo.

\section{Referencial metodológico}

O referencial metodológico empregado neste estudo possui caráter qualitativo, documental/ bibliográfica e descritivo. Primeiramente, cabe dizer que o termo qualitativo utilizado neste artigo implica uma compreensão de "[...] fatos e locais que constituem objetos de pesquisa, para extrair desse convívio os significados visíveis e latentes que somente são perceptíveis a uma atenção sensível" (CHIZZOTTI, 2006, p. 28). Dessa forma, torna-se necessária uma verificação profunda dos fenômenos acerca do álcool combustível no Brasil (objeto de pesquisa) para interpretá-lo à luz do path dependence, abrindo espaço para outra compreensão da situação estudada.

A característica documental/bibliográfica está relacionada à coleta de informações em referências da área (GIL, 2000), cuja base de dados advém tanto do material de origem secundária (disponível na literatura publicada) quanto de origem primária (leis, decretos, relatório de pesquisas etc.).

Este estudo também tem conotação descritiva, porquanto, procura descrever as características de um determinado fato, avançando numa análise prospectiva para o álcool combustível. "A pesquisa descritiva observa, registra, correlaciona e descreve fatos ou fenômenos de uma determinada realidade sem manipulá-los. 
Procura conhecer e entender as diversas situações e relações que ocorrem na vida social, política, econômica e demais aspectos que ocorrem na sociedade" (VALENTIM, 2008, p. 23). Neste caso, o emprego da metodologia descritiva assenta-se na descrição de elementos e/ou características que relacionam a evolução do álcool combustível no Brasil e o path dependence.

Por fim, esta escolha metodológica representa limitações por não conter, por exemplo, declarações e entrevistas de atores envolvidos no problema apresentado. Contudo, outras literaturas disponíveis podem suprir esta lacuna (SHIKIDA et al., 2011).

\section{Aspectos teóricos do path dependence}

O conceito de path dependence foi inicialmente usado para explicar trajetórias tecnológicas (DAVID, 1985; ARTHUR, 1989). O trabalho seminal de David (1985) aplica este conceito para analisar o desenvolvimento do teclado utilizado em computadores. Este autor conclui que, apesar de existirem diversas opções mais eficientes, a disposição das teclas utilizadas nos teclados de hoje é explicada pelas interconexões na produção e na demanda do mercado de datilografia estabelecidas nos anos 1880.

Posteriormente, diversas correntes ligadas à economia institucional extrapolaram este conceito para explicar trajetórias de desenvolvimento das instituições. Neste sentido, os trabalhos de North $(1990,1994,2005)$ aplicam este conceito para explicar a trajetória das regras e instituições e suas implicações sobre o desenvolvimento das nações. Para North (1990), o conceito de path dependence ressalta a importância da trajetória histórica, sendo difícil compreender as escolhas atuais sem entender a evolução das instituições em períodos anteriores. Assim, as escolhas no presente seriam influenciadas pela matriz institucional do passado. Vale ressaltar que isso não implica em inevitabilidade, ou seja, o passado ditando o futuro. Desse modo, as decisões tomadas em um determinado momento dispõem de certo caminho, com padrões novos e antigos interagindo. Fatores como as externalidades de rede, o processo de aprendizagem das organizações e as capacidades tecnológicas (inovações) influenciam a emergência e sobrevivência de instituições.

Com efeito, tal abordagem já tinha sido levantada por David (1985), ao dizer que não é possível descobrir a lógica (ou ilógica) do mundo que se apresenta, exceto pela compreensão decomo ela ficou dessa maneira. Neste contexto, vale frisar que a história importa porque o passado é considerado irreparável, não podendo ser reproduzido ipsis litteris na medida em que as condições iniciais não são mais as mesmas de outrora, de modo que o passado condiciona escolhas presentes (MOREIRA e HERSCOVICI, 2006).

Vasta literatura vem buscando traçar paralelos entre as trajetórias institucionais e evolução biológica. As chamadas teorias evolucionárias trazem insights interessantes acerca dos mecanismos de sobrevivência de instituições e organizações ao longo do tempo.

Las organizaciones, localizadas en regiones y tiempos específicos, generan dinámicas específicas de industrialización, estructuras de gobierno y arreglos institucionales adecuados a contextos determinados, pero que no necesariamente son las más eficientes. La historia importa porque nos permite explicar el proceso [...]. En economía como en biología, sin una perspectiva evolutiva no se puede explicar nada. La formación de empresas y sistemas productivos no es simplemente un proceso de selección de formas organizacionales eficientes, sino un proceso evolutivo de generación de patrones históricos con rasgos de path dependence (HODGSON, 2007, p. 19).

Zysman (1994), unindo a perspectiva institucionalista de North com a tendência evolucionária, salienta que as trajetórias nacionais de crescimento são historicamente determinadas. Neste sentido, os movimentos nacionais, idiossincráticos per se, são parte de um processo de interação e competição em que 
a organização da política e dos mercados dentro de cada economia passa a ser determinante na estruturação institucional, o que acaba refletindo nas decisões dos agentes e, consequentemente, na operação dos mercados.

Na mesma abordagem de Zysman (1994), Conceição (2008) salienta que não é suficiente somente gerar investimento para criar as bases de um processo decrescimento, énecessário construir um ambiente institucional capaz de transformá-lo em crescimento, sendo fundamental o papel desse ambiente na determinação dos padrões do processo inovativo e da capacidade tecnológica.

Technology, like market processes, is not disembodied. It develops in communities; it has local roots. The processes of learning that drive its development are shaped by the community and institutional structure, and consequently the technological trajectories can only be defined in reference to particular societies (ZYSMAN, 1994, p. 261).

Pondé (1997) e Pondé et al. (2005), fazendo menção à integração das principais contribuições da teoria dos custos de transação (como a desenvolvida por Oliver Williamson) com teorizações da dinâmica da concorrência (como a desenvolvida por Richard Nelson e Sidney Winter), reforçam a ideia de que esta integração teórica permite um tratamento não reducionista dos mecanismos causais desencadeados pela concorrência, funcionando como um aporte em torno do qual várias hipóteses sobre a evolução das instituições empresariais podem ser implementadas.

Portanto, na concepção do path dependence, tanto instituições quanto tecnologias tendem a seguir suas trajetórias historicamente construídas, discutindo "mainly to coordination problems, be it coordination to move an industry from one technology to another or from one industry standard to another" (LEVIN et al., 2009, p. 16).

Technological change and institutional change are the basic keys to societal and economic evolution and both exhibit the characteristics of path dependence. Can a single model account for both technological and institutional change? They do have much in common. Increasing returns is an essential ingredient to both (NORTH, 1990, p. 103).

Nesta dinâmica, a trajetória e suas implicações devem ser enfatizadas, pois, conforme Enderle e Guerrero (2008, p. 4), "[...] as trajetórias de crescimento econômico são diversas e heterogêneas, e ocorrem no interior de um processo de constante mudança, sem se saber se para melhor, ou não." É por isto que há a necessidade de compreensão do processo de mudança institucional, não dissociado de um embeddedness e path dependence.

Não obstante, cumpre dizer que o processo inovativo está atrelado à escolha de um determinado padrão tecnológico que se desenvolve a ponto de gerar uma situação de lock-in (rigidez estrutural), na qual a sua mudança se torna difícil. Frisa-se, contudo, que os efeitos de lock in podem acontecer em determinadas situações, mas não é uma “trajetória" inexorável no desenvolvimento de tecnologias. Para Arthur (1989), no caso de lock-in, o grau de dificuldade em modificar as especificidades que proporcionam o arranjo institucional e o padrão tecnológico (que compreende desde a concepção técnica até aspectos financeiros) é que vai determinar a sua trajetória. Por esse motivo, frequentemente, instituições passam a atuar como mecanismos autorreforçantes (self-enforcing), estabelecendo o uso de determinadas tecnologias e, assim, gerando um mecanismo de path dependence.

Neste sentido, North (1990, p. 94) considera como causas do path dependence em tecnologias, que geram situações de lock-in: "os custos fixos significativos, provocando uma redução expressiva dos custos à medida que a produção aumenta; os efeitos de aprendizagem; os efeitos de coordenação, derivados da cooperação entre agentes que enfrentam o mesmo tipo de situação; e as expectativas adaptativas".

Em suma, a ideia, base para o entendimento da proposta da dinâmica do progresso técnico da 
firma, é que a busca por novas rotinas e trajetórias tecnológicas não é randômica nem aleatória, seguindo alguns elementos que permitem que as apostas não sejam ad hoc, mas considera a cumulatividade do conhecimento, o aprendizado, entre outros elementos que guiam as escolhas (como interações organizacionais), de forma que a história importa. Ou seja, as empresas descartam rotinas antiquadas, incorporam novas, outras são aprendidas e/ou apreendidas. É como a carga genética da evolução das espécies, cuja analogia os neo-schumpeterianos - vide Shikida (1997) - utilizam para auxiliar a análise e a proposição da evolução das firmas e o próprio contexto do desenvolvimento técnico-científico.

\section{4. Álcool combustível e path dependence}

Belik (1992), Shikida (1997) e Paulillo et al. (2007) enfatizaram a "orquestração" de interesses como um dos fatores primordiais para a entrada do álcool combustível na matriz energética brasileira. Conforme Shikida (1997, p. 158-159),

A crise do petróleo gerou um "gargalo" no processo produtivo. [...] Contudo, a crise da agroindústria canavieira acabou favorecendo a "orquestração" de interesses que levou o país a optar pelo Proálcool. [...] A “orquestração" de interesses para viabilizar o Proálcool englobou os empresários das usinas e destilarias, o Estado, o setor de máquinas e equipamentos e a indústria automobilística. Para os usineiros tratava-se de diversificar a produção, de criar um novo mercado diante das frequentes crises da economia açucareira, e diante também de um parque produtivo que precisava avançar tecnologicamente e que estava com tendência à sobrecapacidade. Para o Estado, os interesses nesse Programa resumiam-se nos seguintes objetivos: economia de divisas; diminuição das desigualdades regionais de renda; crescimento da renda interna; geração de empregos; e expansão da produção de bens de capital. Para o setor de máquinas e equipamentos (indústria de bens de capital), o advento do Proálcool permitia vislumbrar um quadro de continuidade do crescimento que havia sido iniciado ao final da década de 60 e que atingiu o seu auge no período do "milagre" econômico do país. Especificamente para a indústria automobilística, a crise do petróleo obstaculizava, de certa forma, a continuidade da política de transporte baseada em rodovias; e o carro movido a álcool despontava como uma alternativa para a continuidade dessa política de transporte.

Sobre a relação Estado-agroindústria canavieira, Belik (1992) e Ramos (1999) chamam a atenção para o fato de este setor possuir uma histórica capacidade de articulação, atuando em concordância com os interesses do Estado e de outras organizações privadas em prol de políticas públicas que convirjam para a alavancagem de seus principais produtos (açúcar e álcool) no mercado nacional e internacional.

O álcool combustível, na performance evolutiva do Proálcool (SHIKIDA, 1997) ${ }^{4}$ após passar pela fase de expansão moderada (19751979, cujo carro-chefe consistiu na produção de álcool anidro como aditivo para a gasolina, e que teve patrocínio de um elenco de políticas de crédito, subsídio e preços) e pela fase de expansão acelerada (1980-1985, na qual reforçaram-se os incentivos do Estado para a produção alcooleira, com ênfase no tipo hidratado e com forte estímulo para a venda de veículos movidos exclusivamente a álcool), evidenciou sua primeira fase de desaceleração e crise no período 1986/1995.

4 Sobre a evolução da agroindústria canavieira, com destaque para o Proálcool, ver: Szmrecsányi (1979), Belik (1992), Shikida (1997), Ramos (1999), Moraes e Shikida (2002), Vian (2003), Paulillo et al. (2007), Neves e Conejero (2007) e Souza e Macedo (2009). 
Nesse revés houve uma substancial redução da participação dos investimentos públicos no Programa e desequilíbrio entre a oferta e a demanda de álcool combustível, o que contribuiu para arrefecer o interesse em produzir (na ótica da indústria automobilística) e para comprar um veículo a álcool (na ótica do consumidor). Cumpre dizer que, ao final da década de 1980 e início dos anos 1990, os preços do petróleo caíram (favorecendo o consumo de gasolina), enquanto os preços do açúcar estavam em patamares elevados (direcionando a produção canavieira para esta commodity), sendo fatores importantes na explicação dessa fase crítica do Proálcool.

Assim, no início dos anos 1990, observa-se uma ruptura parcial da "orquestração" de interesses que havia se estabelecido em torno do Proálcool. O Estado, revestido de uma tendência neoliberal e afetado por uma grave crise fiscal e financeira, encerra o paradigma subvencionista outrora existente na agroindústria canavieira. Ocorre a extinção do Instituto do Açúcar e do Álcool (IAA), dando fim aos mecanismos de intervenção na atividade produtiva que iam desde o estabelecimento de quotas de produção, fixação de preços para a cana-de-açúcar, açúcar e álcool, até a concessão de subsídios.

A política de intervenção estatal no complexo canavieiro nacional foi responsável por uma estrutura atrasada e de baixa competitividade que se manteve nos últimos cinquenta anos. A mudança da política e do ambiente institucional, por sua vez, obrigou as empresas a adotarem estratégias diferenciadas das anteriores, buscando a competitividade nacional e internacional (BELIK et al., 1998, p. 8).

Esta ruptura fez emergir o paradigma tecnológico que as usinas e destilarias são obrigadas a assumir para se manterem no mercado, tornando-se primordial a minimização dos custos de produção, o desenvolvimento de novas tecnologias e o aproveitamento intensivo de subprodutos, formas relevantes para uma situação mais concorrencial (SHIKIDA, 1997). Para Fernandes e Coelho (1996, p. 154), "um regime de maior liberdade de atuação deverá aumentar a participação no mercado das empresas mais eficientes que a média e, com isso, tornar o setor mais rentável". E isto foi o que de fato ocorreu, ou seja, as empresas menos preparadas em termos de capacitação tecnológica encerraram suas atividades e/ou foram incorporadas pelas mais dinâmicas do setor. De acordo com Fortes (2009, p. 1), "de 2000 a setembro deste ano [2009], o setor de açúcar e álcool contou com 99 fusões e aquisições envolvendo empresas brasileiras".

De 1996 ao início dos anos 2000 houve uma breve recuperação do crescimento da produção alcooleira, mas logo seguido de outro declínio, decorrente, em parte, dos incentivos econômicos que o uso do gás natural veicular (GNV) trouxe, o que contribuiu para a migração de parte da frota de carros nacionais para o GNV. Outrossim, ficava evidente o cenário de rearranjo da agroindústria canavieira sob a égide da desregulamentação setorial, em que "o papel do Estado mudou, ele agora é mais de coordenador do que interventor" (VIAN, 2003, p. 11). Com efeito, no início da década de 90 o preço do açúcar no mercado interno deixou de ser tabelado; a partir de 1994, as exportações açucareiras foram liberadas; em 1997, o preço do álcool anidro também deixou de ser tabelado; as liberações dos preços da cana-de-açúcar e do álcool hidratado ocorreram, respectivamente, em 1998 e 1999 (ALVES, 2002).

A partir da safra 2000/01 observa-se uma terceira fase, na qual o álcool combustível passou a conviver com uma perspectiva de elevado crescimento, em função da crescente necessidade de reduzir as emissões de gases de efeito estufa (a produção de álcool da cana-de-açúcar e o consumo desse produto, enquanto substituto da gasolina, oferece vantagens neste aspecto) e com uma inovação que mudou consideravelmente a dinâmica do setor, a introdução do carro bicombustível - que permite tanto o uso da gasolina quanto o de álcool, ou de um mix entre ambos os combustíveis. Cabe citar, com base em dados da Unica (2011), que as vendas de 
carros bicombustíveis representaram, em 2008, aproximadamente $90 \%$ do total de veículos comerciais leves vendidos no Brasil, sendo que, em 2003, esta proporção era de apenas 3,7\%.

A Figura 1 mostra a evolução da produção de álcool total no Brasil. Da safra 1975/76 até a 1985/86 verifica-se uma evolução na produção alcooleira (taxa de crescimento médio de $34,7 \%$ ao ano), corroborando as fases de expansão moderada e acelerada do Proálcool. Da safra 1986/87 até a 2000/01 houve uma fase de desaceleração, crise e instabilidade da produção alcooleira nacional (o parco crescimento médio de $1,25 \%$ ao ano reflete isto). A partir de então se constata um segundo ciclo expansivo para o setor (safras 2001/02 e 2008/09, crescimento médio de $12 \%$ ao ano). Para todo o período considerado (1975/76 a 2008/09), a taxa de crescimento médio anual da produção alcooleira do Brasil foi de 7,7\% .

Essa nova fase de expansão do etanol no Brasil também foi marcada por significativo aporte de investimento estrangeiro. Apesar de até 2009 a participação estrangeira no setor não ultrapassar $27 \%$, investidores internacionais dão cada vez mais sinais de interesse na agroindústria canavieira em função das oportunidades abertas pela desregulamentação setorial iniciada na década de 1990 e de expectativas favoráveis de crescimento dos mercados açucareiro e alcooleiro (este capitaneado pela elevação da demanda por álcool combustível por causa da frota flex). No final da década de 1990 e início da década seguinte, o investimento direto estrangeiro (IDE) na agroindústria canavieira concentrava-se nas categorias refino, moagem de açúcar e usinas de açúcar; a partir de 2002 começa o IDE na categoria produção de álcool, que passou de US\$ 4 milhões em 2002 para mais de US\$ 1 bilhão em 2007 (CARDOSO et al., 2009).

Da mesma forma que a "orquestração" de interesses foi um dos fatores primordiais para a entrada do álcool combustível na matriz energética, seus rearranjos institucionais e tecnológicos vêm condicionando determinadas trajetórias, gerando path dependence em favor do álcool combustível. Sobre este aspecto, o presente artigo se concentra na análise do ambiente de "orquestração" de interesses responsável pela viabilização do álcool combustível e no ambiente de ruptura institucional que levou o Estado a desregulamentar o setor, o que fez emergir o paradigma tecnológico como forma relevante

Figura 1. Evolução da produção de álcool total no Brasil e aspectos caracterizadores.

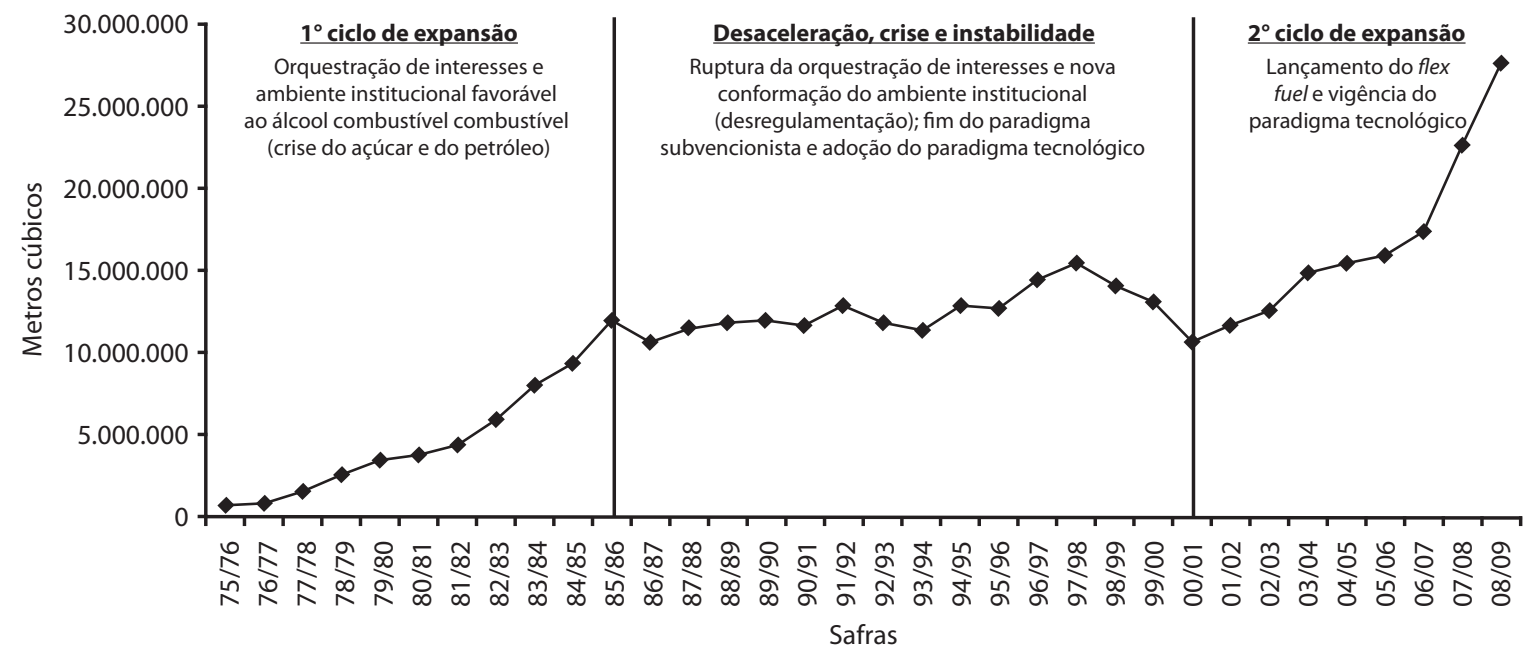

Fonte: Dados dos anos-safras: Alcopar (2011); aspectos caracterizadores: dados da pesquisa. 
para uma situação mais concorrencial, discutindo-os à guisa do conceito teórico de path dependence.

Os empresários das usinas e destilarias, desde o início do Proálcool em 1975, e mesmo no período de desaceleração, crise e instabilidade da produção alcooleira (1986/87-2000/01), mantiveram suas estruturas produtivas voltadas para o açúcar e/ou álcool, direcionando suas produções de acordo com as vicissitudes dos preços dessas duas commodities nos mercados interno e externo. Neste contexto, é importante destacar que, mesmo com a mudança de gerir o setor pelo Estado, de intervencionista para coordenador (VIAN, 2003), os empresários das usinas e destilarias em sinergia com a indústria de bens de capital, centros de pesquisa, organizações corporativistas e também o Estado - mesmo em um panorama de desregulamentação, o Estado manteve sua preocupação com a questão da segurança energética nacional -, aperfeiçoaram continuamente a sustentabilidade tecnológica da cadeia produtiva da agroindústria canavieira, de modo a promover a evolução da produtividade agrícola e industrial da cana-de-açúcar, açúcar e álcool. Destarte, muito do avanço tecnológico coube às ações do Centro de Tecnologia Canavieira (CTC), que deixou de pertencer a um grupo de usinas cooperadas da Copersucar, passando a ser financiada por usinas de todo o País, e ao extinto Programa Nacional de Melhoramento da Cana-de-Açúcar (Planalsucar), este incorporado pela Rede Interuniversitária para Desenvolvimento do Setor Sucroalcooleiro (Ridesa), constituída por sete universidades federais (do Paraná, São Carlos, Viçosa, Rural do Rio de Janeiro, Goiás, Alagoas e Rural de Pernambuco - UFPR, UFSCar, UFV, UFRRJ, UFG, Ufal e UFRPE, respectivamente). De acordo com Cezar (2008, p. 40), "esses dois centros permitiram que o Brasil saísse de pouco mais de 3 mil litros de álcool por hectare, no fim dos anos 70, para mais de 7 mil litros de álcool por hectare atualmente" (para efeito de cotejo, hoje a produtividade do álcool de beterraba é de 5,4 mil litros/ha, enquanto a produtividade do álcool de milho é de 3,1 mil litros/ha). A produção de cana-de-açúcar saiu de pouco mais de 50 toneladas por hectare, em média, em meados dos anos 70, para uma média de aproximadamente 80 toneladas por hectare na década de 2000. E há perspectivas de mais crescimento da produtividade a partir do etanol de resíduo celulósico (de rejeitos do bagaço e palha da cana). Isto, aliado ao fato de o País contar com produção de açúcar e álcool para o mercado durante o ano todo, contribui para que a oferta de álcool combustível seja cada vez mais elástica.

Afora o estímulo dado ao ambiente tecnológico do álcool pelos dois centros de pesquisa supracitados, o Banco Nacional de Desenvolvimento Econômico e Social (BNDES) e Centro de Gestão e Estudos Estratégicos (CGEE) (2008) salientam que os avanços nos indicadores de produtividade da agroindústria canavieira em geral, e em particular para o álcool, derivaram principalmente de inovações biológicas, físico-químicas, mecânicas, do reaproveitamento mais intensivo do bagaço para a cogeração de energia e de inovações associadas às novas formas de organização do trabalho, métodos de produção e gerenciamento global da produção agrícola e industrial. Neste contexto, vale lembrar que tais avanços foram também conseguidos pela sinergia com outras empresas produtoras de tecnologia e centros de pesquisa como, por exemplo, o Instituto Agronômico de Campinas (IAC), Instituto de Pesquisas Tecnológicas (IPT), Instituto de Tecnologia de Alimentos (Ital), Instituto Biológico, além de três universidades estaduais [Universidade de São Paulo (USP), Universidade Estadual de Campinas (Unicamp) e Universidade Estadual Paulista Julio de Mesquita Filho (Unesp)], que contêm vários cursos e grupos de pesquisas voltados para o desenvolvimento científico e tecnológico da agroindústria canavieira, fundamental para o processo de expansão com incrementos de produtividade observados nesse setor.

Macedo (2007), por intermédio do Quadro 1, sintetiza e periodiza alguns itens que foram importantes para a modernização tecnológica do processo produtivo da cana-de-açúcar e do álcool, como as novas e mais produtivas variedades de 
cana, os avanços das técnicas de produção de cana (fertirrigação, colheita mecanizada etc.) e álcool (fermentação) e o desenvolvimento dos motores bicombustíveis.

Com estes avanços tecnológicos do processo produtivo da cana-de-açúcar e do álcool, Macedo (2007) aponta ganhos de $8 \%$ na qualidade da matéria-prima (medida em teor de açúcar na cana), ganhos de $130 \%$ na produtividade da fermentação (medida em metros cúbicos de álcool por metro cúbico de reator) e ganhos de $14 \%$ na conversão dos açúcares na cana para álcool. Em Veiga Filho (2008, p. 12) há um indicador de custo que retrata as vantagens e ganhos competitivos que a curva de aprendizado do álcool combustível proporciona ao Brasil vis-à-vis outros competidores internacionais, qual seja, "na bomba, o álcool da cana bate de longe o etanol do milho, saindo a US\$ 0,20 , diante de quase US\$ 0,40 no caso do produto americano".

Como o álcool pode ser extraído da hidrólise e fermentação de materiais lignocelulósicos, há ainda que se considerar o chamado álcool de segunda geração, oriundo do processamento de lignocelulose, neste caso, de resíduos de cana-de-açúcar (rejeitos do bagaço e palha). Os principais programas de pesquisa e desenvolvimento, em escalas experimentais de produção (com resíduos de madeiras e lixo orgânico, principalmente), estão sendo conduzidos nos Estados Unidos e na Europa, mas várias pesquisas já começaram a serem feitas no Brasil a partir do aproveitamento de resíduos da cana-de-açúcar. Conforme
Goldberg (2008) e Unica (2011), com o álcool de segunda geração sendo produzido no Brasil, a agroindústria canavieira poderá elevar a produtividade do álcool de 7 mil litros por hectare produzidos nas últimas safras para algo em torno de 13 mil litros de álcool por hectare. Dessa forma, não seria necessário expandir a área cultivada, aproveitando-se fundamentalmente da expertise e da estrutura existente na agroindústria canavieira. Contudo, de acordo com Abramovay (2008, p. 45):

The US Department of Energy (DOE),
for instance, is investing USD 1 billion in
the construction of experimental refineries
designed to transform vegetable matter into
alcohol. In Brazil, only now is something
similar happening with the announcement of
the Bioethanol Science and Technology Center,
which is to receive BRL 50 million in the next
five years [...]. The Brazilian investment in
cellulosic ethanol, so far, is meager, which
entails the risk that the country might very
quickly lose the technological edge it holds
today in the ethanol area.

Nessa linha de busca de maior produtividade, o processo de transformação de uma forma de energia em mais outra forma de energia, conhecido como cogeração, encontra na queima do bagaço da cana-de-açúcar uma excelente fonte de energia para o processamento industrial da cana e, consequentemente, produção de açúcar

Quadro 1. Alguns dos principais avanços tecnológicos do processo produtivo da cana-de-açúcar e do álcool (1980-1990 e 1990-2000).

\begin{tabular}{|c|c|}
\hline Período 1980-1990 & Período 1990-2000 \\
\hline $\begin{array}{l}\text { A introdução em larga escala de variedades de cana desenvol- } \\
\text { vidas no Brasil (principalmente do CTC-Copersucar e do Pla- } \\
\text { nalsucar). } \\
\text { O desenvolvimento do uso integral da vinhaça na fertirrigação. } \\
\text { Controles biológicos na produção da cana. } \\
\text { Desenvolvimento do sistema de moagem com quatro rolos. } \\
\text { Tecnologia para operação de fermentações "abertas" de grande } \\
\text { porte. } \\
\text { Aumento na produção de energia elétrica na indústria (autos- } \\
\text { suficiência). } \\
\text { Uso final: especificações do etanol; motores E-100; transporte, } \\
\text { mistura e armazenamento do álcool. }\end{array}$ & $\begin{array}{l}\text { Otimização do corte, carregamento e transporte da cana. } \\
\text { Mapeamento do genoma da cana; transformações genéticas. } \\
\text { Mecanização da colheita. } \\
\text { Obtenção de excedentes de energia elétrica e venda para a con- } \\
\text { cessionária. } \\
\text { Avanços em automação industrial. } \\
\text { Avanços no gerenciamento técnico (agrícola e industrial). } \\
\text { A introdução dos motores bicombustíveis. }\end{array}$ \\
\hline
\end{tabular}

Fonte: Macedo (2007, p. 158). 
e/ou álcool. Isto porque, após a extração do caldo é possível queimar o bagaço em caldeiras apropriadas, produzindo energia térmica, que é transferida para movimentação de máquinas e turbinas no próprio processamento da cana, tornando-se um destacado item na composição dos custos de produção do álcool e açúcar oriundos da cultura canavieira (SOUZA, 2002). “É importante frisar que as usinas e destilarias são autossuficientes na produção de energia elétrica, por meio da cogeração ou bioeletricidade" (UNICA, 2008, p. 9), com possibilidade de comercialização do excedente de energia produzida com as distribuidoras locais de energia elétrica. A importância da cadeia bioenergética da cana-de-açúcar no Brasil (composta pelo álcool combustível e pela energia oriunda da queima do bagaço da cana) representou, em 2007, 16\% na matriz energética nacional (BNDES e CGEE, 2008). Ademais,

[...] no início de 2008, as usinas de açúcar e etanol brasileiras apresentavam um potencial médio de geração de excedentes de energia equivalente a 1.800 Megawatts Médios (MWm), o que corresponde a apenas 3\% das necessidades do Brasil. Com o aumento da utilização de biomassa da cana-de-açúcar e a implementação de caldeiras de alta eficiência, estimativas sugerem que, até 2015 essa geração poderia aumentar para até $11.500 \mathrm{MWm}$, ou $15 \%$ da demanda de energia elétrica do País. [...] A bioeletricidade gerada a partir da cana-de-açúcar é uma opção particularmente interessante para o Brasil porque a maior parte da eletricidade do País vem de grandes usinas hidrelétricas. O período de colheita da cana-de-açúcar, no qual a maior parte da biomassa está disponível, coincide com a estação seca, quando as usinas hidrelétricas diminuem sua produção devido à redução nos níveis de seus reservatórios (UNICA, 2008, p. 10).
Além dessa busca por desenvolvimento de novas competências visando aumentar cada vez mais a eficiência técnica do álcool, houve preocupação com a modernização da estrutura organizacional e institucional das firmas, buscando, inclusive, outros mecanismos de coordenação corporativistas junto aos setores públicos e privados como, por exemplo, na criação da Unica, em São Paulo (as 119 companhias associadas à Unica respondem por mais de 50\% do álcool e $60 \%$ do açúcar produzidos no Brasil) ou em outras representações dessa natureza nos demais estados expressivos no contexto da agroindústria canavieira (Alcopar, no Paraná, Sindicato da Indústria de Fabricação do Álcool no Estado de Minas Gerais/Sindicato da Indústria do Açúcar no Estado de Minas Gerais - SIAMIG/ SINDAÇÚCAR-MG etc.). A Câmara Setorial do Açúcar e do Álcool, criada pelo Ministério da Agricultura, Pecuária e Abastecimento (Mapa) em maio de 2003, constituída por representantes patronais, governamentais e representantes da classe trabalhadora, é outro arranjo institucional que objetiva discutir coletivamente os problemas da cadeia e buscar soluções para os seus problemas.

A Câmara Setorial do Açúcar e do Álcool
é um fórum de discussões, no qual estão
presentes entidades representativas
do Estado, da iniciativa privada e dos
trabalhadores. A presença do Estado na
Câmara é de grande relevância, visto que
diminui a assimetria de informações com
o setor privado. Assim, a Câmara Setorial
é uma ferramenta de interação do setor
privado junto ao Estado para melhor ada-
ptar os ambientes institucional, tecnoló-
gico e organizacional às necessidades do
setor sucroalcooleiro (GONÇALVES JR.
et al., 2009, p. 205).

O Consecana (Conselho dos Produtores de Cana-de-Açúcar, Açúcar e Álcool), existente em São Paulo, Paraná, Alagoas, Pernambuco 
etc., é uma associação civil sem fins lucrativos, com estatuto e regulamentos próprios, cujo escopo principal tem sido a divulgação mensal dos valores de referência do preço da tonelada de cana-de-açúcar com base nos preços dos produtos finais (açúcar e álcool) obtidos dessa matéria-prima. Trata-se de um instrumento que procura zelar pelo aprimoramento do sistema de avaliação da qualidade da cana-de-açúcar, que é "expressa pela concentração total de açúcares (sacarose, glicose e frutose) recuperáveis no processo industrial e expressos em quilograma por tonelada de cana" (SACHS, 2007, p. 58).

No referencial do path dependence está evidente a evolução em termos de trajetórias tecnológicas e institucionais privilegiando a busca de competências complementares às competências já adquiridas (NORTH, 1990). É o caso da busca pela maior produtividade de álcool produzido, com aperfeiçoamentos técnicos, e também na criação de novos arranjos institucionais (Câmara Setorial do Açúcar e do Álcool, Unica, Consecana etc.) que objetivam não só organizar o setor como defender os interesses dos produtores de cana, açúcar, álcool e bioeletricidade. Com efeito, estas novas formas de conciliar as necessidades e interesses dos agentes que integram a agroindústria canavieira mostram as inovações institucionais que o setor fez para melhor se adaptar ao mundo real. Conforme Enderle e Guerrero (2008, p. 4), "as instituições são habitualmente um processo rotinizado do comportamento humano prevalecente no ambiente social, cultural, político e econômico que evoluem através de um processo seletivo e adaptativo".

Afora esses ganhos tecnológicos dentro da usina, o setor de máquinas, tratores, colheitadeiras e caminhões (indústria de bens de capital), também articulado institucionalmente com a agroindústria canavieira, posto ser seu fornecedor de equipamentos, vem aprimorando as tecnologias de transporte, plantio, colheita e processamento industrial nos diversos departamentos da agroindústria canavieira. Como exemplo, as unidades industriais vêm implementando melhorias como a substituição de caldeiras de alta pressão (favorecendo a cogeração de energia), modernizando-se, mormente, com a aplicação cada vez mais crescente da automação eletrônica nas máquinas e equipamentos (BOUÇAS, 2008).

Este comportamento da indústria de bens de capital ligada à agroindústria canavieira mostra o engajamento pela busca de resultados competitivos também no setor a montante. Ou seja, as novas escolhas técnicas se tornam uma função da história, que, por sua vez, deriva do ambiente institucional capaz de transformá-la em crescimento, daí a necessidade de externalidades positivas de setores ligados à produção de álcool. É neste tipo de interação dinâmica que toda a economia alcooleira ganha, isto é, as melhorias das capacidades tecnológicas de um segmento acabam favorecendo um outro; aqui os avanços na indústria de bens de capital refletem positivamente para que a agroindústria canavieira também melhore suas capacidades tecnológicas.

Valendo-se da citação anterior de BNDES e CGEE (2008), que atesta maior profusão do ambiente tecnológico e de pesquisas para São Paulo, e sendo este estado sede dos polos de produção de máquinas e equipamentos para a agroindústria e agricultura canavieira, centrados no eixo Piracicaba-Sertãozinho-Ribeirão Preto, têm-se estruturas socioeconômicas enraizadas, garantindo que São Paulo seja economicamente mais eficiente que os outros estados do Brasil.

Outro importante agente no ambiente institucional que colabora para que o álcool combustível mantenha o path dependence é a indústria automobilística, sobretudo após a introdução do carro bicombustível. Conforme Siqueira e Siqueira (2004), devido à necessidade de substituir a gasolina, em face da instabilidade dos preços do petróleo e da maior emissão de poluentes que a queima dos derivados do petróleo acarreta, foram feitas, no final da década de 1980, pesquisas nos Estados Unidos, Europa e Japão com vistas a desenvolver a tecnologia flex fuel. Aprimorada ainda mais no final da década de 1990, principalmente no Brasil, esta nova tecnologia consegue realizar, por meio de sensores avançados de controle de mistura e ignição, com 
que um motor seja capaz de reconhecer e adaptar automaticamente suas funções de gerenciamento para qualquer proporção de mistura de álcool e gasolina que esteja no tanque, não demandando qualquer ação por parte do motorista. De acordo com BNDES e CGEE (2008), existem mais de 60 modelos diferentes de veículos bicombustíveis, fabricados por dez montadoras de origem americana, europeia e japonesa, instaladas no País. Essa nova demanda pode ser apontada como o principal motivo da expansão da produção alcooleira nos últimos anos no Brasil, que ainda se soma às possibilidades de expansão da demanda internacional de álcool para misturas com a gasolina. "Os veículos equipados com esses motores têm representado a maioria dos veículos novos vendidos no Brasil a partir de 2005 e, desde então, vêm se aperfeiçoando, em termos de desempenho e funcionalidade dos sistemas de partida a frio" (BNDES e CGEE, 2008, p. 43).

Esta é uma situação em que um dado padrão tecnológico (neste caso na tecnologia flex fuel) se generaliza e se aperfeiçoa, tornando extremamente difícil sua mudança, levando, por consequência, ao fenômeno de path dependence, ou seja, o fato de as possibilidades de escolha no presente serem condicionadas pelas escolhas passadas, em que os bons resultados do aumento da produtividade álcool-energética foram sendo conseguidos ao longo do tempo. Isto vem de encontro com o que Hodgson (2007) expôs anteriormente, ou seja, a formação de sistemas de produção não é simplesmente um processo de seleção de formas organizacionais eficientes, mas um processo evolutivo de geração de padrões históricos com características de path dependence.

Outrossim, o comportamento do álcool combustível moldado por organizações e agentes econômicos no Brasil não pode prescindir de uma análise da ação estatal. O Estado, cujos interesses iniciais no Proálcool resumiam-se na busca pela segurança energética, economia de divisas, diminuição das desigualdades regionais de renda, crescimento da renda interna, geração de empregos e expansão da produção de bens de capital, agora atua mais como um agente regulador da atividade sucroalcooleira, o que significa que a produção e a comercialização da cana, açúcar e álcool não se sujeitam mais a controles do Estado como em outrora (época do IAA). Ainda assim, é necessário estabelecer mecanismos legais para que todos os 35.500 postos de abastecimento de combustível comercializem o álcool hidratado, além de exigir que as distribuidoras de combustíveis adquiram o álcool anidro das destilarias para fazer uma mistura com a gasolina na proporção que pode variar entre $20 \%$ e 25\% de anidro (Lei Federal n. 8.723/93).

O desenvolvimento dessa notável infraestrutura resultou de um esforço iniciado nos primórdios do Proálcool e foi sendo consolidada ao longo do tempo. É imperativo reconhecer que, sem a determinação política para criar tal infraestrutura e sem o apoio das empresas de distribuição de combustíveis e da Petrobras, que durante anos se responsabilizou pela aquisição, mistura e distribuição do bioetanol puro em mistura com gasolina, a experiência brasileira com o bioetanol não teria a importância que alcançou (BNDES e CGEE, 2008, p. 64).

Em termos de política pública, um mecanismo de apoio ao setor alcooleiro se dá via Programa de Financiamento à Estocagem de Álcool e mediante política diferenciada de preços dos carros a álcool ou bicombustíveis, com vistas "a internalizar no preço de mercado a vantagem ambiental propiciada pelo veículo que utiliza, ou pode utilizar exclusivamente etanol" (UNICA, 2007, p. 29). Ainda de acordo com a Unica, a tributação ao álcool combustível concentra-se no produtor e na distribuidora de combustíveis, e no caso de exportação do álcool, hidratado ou anidro, não há tributação em virtude de imunidade constitucional tributária. A Cide (Contribuição de Intervenção no Domínio Econômico), mediante isenções fiscais e regulações, "tem contribuído para garantir a competitividade do álcool em relação à gasolina" (PAULILLO et al., 2007, p. 542), sobretudo na obrigatoriedade da mistura 
de álcool anidro na gasolina (que varia de 18\% a $25 \%$ ), mostrando que a relação do Estado com a agroindústria canavieira ainda mantém certos mecanismos corporativistas em prol de uma maior segurança energética.

Neste contexto, por meio do Decreto n. 3.546, de 2000, foi criado o Conselho Interministerial do Açúcar e do Álcool (Cima), composto pelos ministros da Agricultura, Pecuária e Abastecimento (que o preside), da Fazenda, do Desenvolvimento, Indústria e Comércio Exterior e de Minas e Energia, cujo escopo é o de realizar políticas a fim de adequar a participação dos produtos de cana-de-açúcar na matriz energética brasileira, procurar mecanismos econômicos necessários para a autossustentação setorial e promover o desenvolvimento científico e tecnológico do setor. Neste sentido, embora o Ministério da Ciência e Tecnologia não faça parte do Cima, sobretudo por meio do Conselho Nacional de Desenvolvimento Científico e Tecnológico (CNPq), o mesmo atua como importante alavancador da pesquisa e desenvolvimento no setor (SHIKIDA et al., 2011).

Com o propósito de ampliar a participação no mercado alcooleiro, a Petrobras (uma empresa estatal) pretende investir US\$ 1,5 bilhão em biocombustíveis entre 2008 e 2012, sendo 46\% em dutos e alcooldutos. Um dos alcooldutos que deverá ser construído vai ligar áreas produtoras de Goiás, Minas Gerais e São Paulo aos portos do Rio de Janeiro e São Paulo; o outro alcooduto deverá ligar áreas produtoras de Mato Grosso do Sul e Paraná ao porto de Paranaguá (PR). Ambos os investimentos preveem parcerias público-privadas (GOLDBERG, 2008). Völz et al. (2009) ressaltam que o transporte de álcool para exportação é realizado via modal ferroviário e/ ou rodoviário, fator este encarecedor no processo logístico. Com a implantação do alcoolduto, os custos de transporte tendem a reduzir em até $70 \%$, aumentando ainda mais a competitividade das unidades produtoras do Brasil.

Nota-se, pois, que ao tentar resolver problemas de ordem logística, a Petrobras e outras firmas impulsionam a continuidade da política energética vinculada ao álcool combustível, buscando novas capacidades tecnológicas condicionadas pela trajetória histórica (no caso, da necessidade de uma maior dinâmica competitiva para oálcool). Esta lógica é coerente com o previsto pelo referencial teórico do path dependence, na medida em que se permite baixar custos de transporte a partir da escolha de um dado padrão tecnológico vislumbrado com o alcooduto. Outro aspecto interessante é que o core business da Petrobras avança também sobre o álcool, mostrando a expressão que este combustível vem tendo no cenário da matriz energética nacional.

A questão ambiental, também vinculada ao interesse estatal, visto que o Brasil é signatário do Protocolo de Kyoto (tratado internacional em que a maioria dos países estipulou compromissos para reduzir a emissão de gases do efeito estufa em 5,2\% em relação aos níveis de 1990, no período entre 2008 e 2010 - o Brasil apesar de signatário não é do anexo 1 (países desenvolvidos) e por isso não tem meta de redução em Kyoto), encontra no consumo de álcool combustível uma possibilidade de redução de emissões de monóxido de carbono, óxidos de enxofre e de compostos orgânicos tóxicos, como benzeno, tolueno, xileno e butadieno. Ademais, o álcool apresenta baixa toxidez e elevada biodegradabilidade. Segundo apontamentos de Veiga Filho (2008), o consumo de álcool no transporte evitou a emissão de 644 milhões de toneladas de gás carbônico desde 1975, quando o Proálcool foi implementado. Para Saldiva et al. (2010), é alto o dano da gasolina à saúde pública, como por exemplo: se todos os carros da Grande São Paulo rodassem somente com a gasolina, haveria mais de 400 mortes por ano em decorrência da poluição. Outro fator benéfico ao álcool é a relação comparativa entre a energia renovável produzida e a energia fóssil usada, que é de 8,9 para o álcool de cana-de-açúcar no Brasil. Apenas para cotejo, quando se considera o álcool de milho (nos EUA), essa relação está entre 1,3-1,8; para o álcool de beterraba (como o produzido na Alemanha) essa relação é próxima de 2,0; já a produção de gasolina e diesel resulta em eficiência energética negativa (SOUZA e MACEDO, 2010; UNICA, 2011). 
Entre as principais ameaças à manutenção desta trajetória de crescimento do álcool combustível colocam-se desafios importantes associados à formação de um mercado internacional para esta commodity. Embora os incrementos tecnológicos tragam uma oportunidade para a consolidação do mercado internacional do álcool, dada pela melhoria da curva de aprendizagem observada nos últimos anos na produção e uso desse combustível alternativo, existem restrições impostas ao comércio do produto, como é o caso dos Estados Unidos, que têm uma taxação de US\$ 0,54 imposta por galão de etanol importado. Falta também regulamentação internacional em termos de estabelecimento de padrões socioambientais para produção de biocombustíveis. Como na maioria dos países, os biocombustíveis ainda têm custo superior ao dos derivados de petróleo (UNICA, 2007; PIRES e SCHECHTMAN, 2010) e a demanda internacional ainda se mostra muito dependente dos mandatos nacionais que estabelecem padrões socioambientais variados (PEROSA e AZEVEDO, 2011). Isto, de certa forma, dificulta a formação de um mercado mundial para o álcool, visto que inexiste um consenso acerca dos padrões socioambientais necessários para produzir biocombustíveis.

Mesmo internamente, também se observam ameaças ao arranjo iniciado no Proálcool e que, mesmo após o final deste Programa, ainda orientam a trajetória do setor no Brasil. A descoberta das reservas pré-sal são relevantes neste sentido e podem criar condições para a ruptura das coalizões que vêm sustentando o álcool combustível. "Não se podem desconsiderar as perspectivas do pré-sal, que em alguns anos implicará importantes investimentos na extração e refino do petróleo, aumentando substancialmente a produção de petróleo e derivados" (JANK, 2010, p. 12). Embora o álcool tenha muitas instituições a quem deva orientações políticas (advindas dos ministérios da Agricultura, Pecuária e Abastecimento, Fazenda, Desenvolvimento, Indústria e Comércio Exterior e de Minas e Energia), isto se torna problemático quando há falta de sintonia ou assimetria de informações entre os ministérios.
Ademais, o desenvolvimento de tecnologia substituta observada, por exemplo, nos carros elétricos, desponta como uma alternativa técnica e ambientalmente correta $^{5}$ para adentrar no mercado automotivo, segundo apontam algumas previsões. "A report by IDTechEx, a research consultancy based in Cambridge, England, reckons a third of the cars made in 2025 will be electrically powered in one way or another. If that trend continues, liquid fuels might become as obsolete as photographic film" (THE ECONOMIST, 2009, p. 1). Contudo, verificam-se ainda algumas restrições ao desenvolvimento dessa tecnologia. Desvantagens comoa autonomia reduzida dos carros elétricos e insuficiência de uma rede de abastecimento de energia para este tipo de veículo estão sendo analisadas pelas empresas que operam nesta atividade (THE ECONOMIST, 2009). A possibilidade de o motor elétrico ser recarregado automaticamente reduziria esse problema, trazendo resultados nítidos em termos de economia de combustível líquido (AVERBUG, 2007). Porém, essa tecnologia ainda não está disponível a custos viáveis.

Existe também a opção de carro híbrido, que pode rodar tanto por combustão quanto por energia elétrica, devido à existência de um motor elétrico acoplado a um propulsor a combustível líquido (gasolina, álcool etc.). Essa modalidade já vem sendo considerada como a principal alternativa no médio prazo para reduzir os problemas de autonomia dos carros elétricos. Ainda assim, a adoção de incentivos para o desenvolvimento desta tecnologia enfrenta resistência de setores ligados à produção de etanol. Como mais uma prova do arranjo institucional em torno da agroindústria canavieira, o governo brasileiro ainda não se posicionou em relação a esta nova tecnologia.

Desta forma, o etanol de primeira geração está longe de representar uma escolha definitiva e vitoriosa como substituto de combustíveis fósseis no mundo (THE ECONOMIST, 2010). As ameaças

\footnotetext{
5 Desde que a energia utilizada seja proveniente de fontes limpas, como a solar, ou advinda de hidrelétricas.
} 
Figura 2. Principais aspectos do path dependence no álcool combustível no Brasil e ameaças.
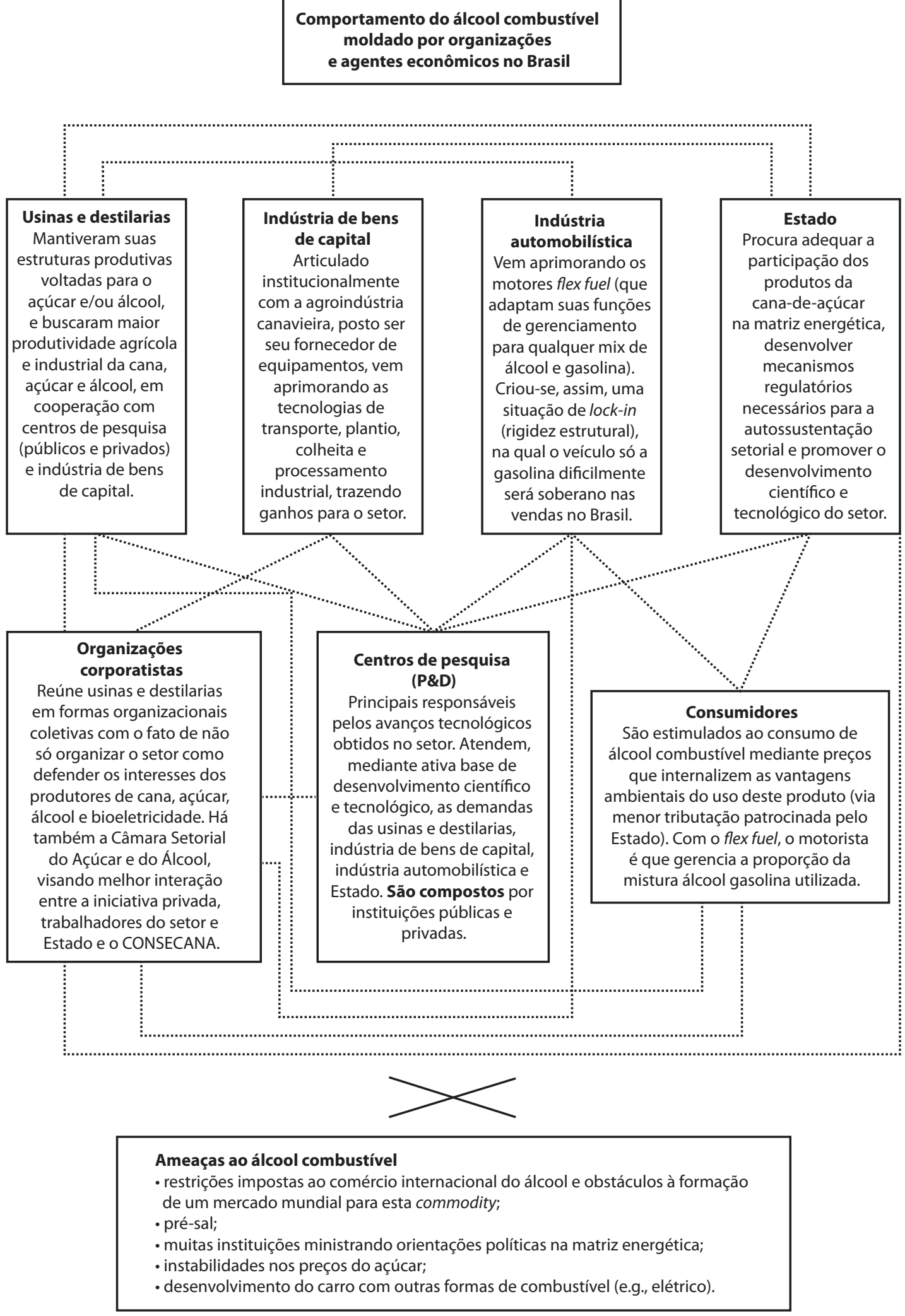

Fonte: Dados da pesquisa. 
internas e externas advindas de novas tecnologias baseadas na biomassa (etanol celulósico, butanol etc.), em outras fontes renováveis (eletricidade, hidrogênio, solar etc.) ou até mesmo no uso mais eficiente do petróleo podem destituir a liderança do etanol construída ao longo dos últimos 25 anos. A necessidade de se desenvolver novas tecnologias para o uso mais eficiente da cana ainda é tratada de maneira pouco séria no País, abrindo espaço para empresas estrangeiras que investem pesado em novos processos para fazer um melhor aproveitamento desta matéria-prima (PEROSA, 2010). Nesse caso, repetir-se-ia história comum na agricultura brasileira e o Brasil também se tornaria um fornecedor de matérias-primas para produção de bioenergia.

A Figura 2 sintetiza os principais aspectos do comportamento do álcool combustível moldado por organizações e agentes econômicos no Brasil (path dependence). Com o Proálcool, o álcool combustível passou a fazer parte da matriz energética brasileira e vem se mantendo nessa posição frente a novas tecnologias disponíveis. Isso significa que foi escolhido um caminho, com uma imbricada atuação de organizações (usinas e destilarias, indústria de bens de capital, indústria automobilística, Estado, organizações corporativistas, centros de pesquisa) e agentes econômicos (consumidores) interessados, direta ou indiretamente, na manutenção da rota optada. Esta matriz institucional apresenta-se locked in (o que obstaculiza o desenvolvimento técnico e econômico de outras fontes similares/ alternativas ao álcool combustível), reforçando o caráter de path dependence sobre a rota escolhida originalmente. Mesmoassim, existem perspectivas que ameaçam o álcool combustível retratadas na figura. De qualquer forma, as histórias pretéritas das organizações supracitadas, por estarem vinculadas aos estoques de conhecimentos e capacidades tecnológicas que adquiriram ao longo de suas trajetórias, num processo de interação com a economia alcooleira, são as definidoras da matriz institucional atual que sustenta o álcool combustível, ao mesmo tempo em que estão moldando a matriz institucional futura.

\section{Conclusões}

Este trabalho teve como objetivo analisar a relação de path dependence no sistema econômico e institucional do álcool combustível no Brasil. A proposição deste estudo consistiu no fato de a "orquestração" de interesses, as trajetórias tecnológicas e as novas conformações institucionais pós-desregulamentação setorial configurarem um mecanismo de path dependence para este importante produto da matriz energética nacional.

Primeiramente, esta proposição foi confirmada. A dinâmica de interação retratada na Figura 2, evidenciando o comportamento do etanol moldado por organizações e agentes econômicos no Brasil, revela a "orquestração" de interesses observada na agroindústria canavieira em torno do álcool combustível. Nessa evolução histórica, à guisa do path dependence, viu-se que interesses diversos, porém imbricados, apoiaram o etanol como a opção energética mais adequada para a substituição de derivados de petróleo (gasolina e diesel). Por conta disso, o etanol e o bagaço de cana representam, em 2011, perto de $16 \%$ da matriz energética brasileira. Ademais, o uso do álcool combustível no Brasil tem crescido apesar da fase de desaceleração, crise e instabilidade na produção de etanol (1986/87 a 2000/01), especialmente após a introdução do flex fuel em 2003.

Não obstante, para o etanol se torna vital a continuidade do desenvolvimento de novas tecnologias e aproveitamento substancial dos subprodutos da cana (principalmente o bagaço), fatos que redundam em minimização dos custos de produção, isto porque, devido à forte dinâmica tecnológica do setor automobilístico, outros concorrentes do etanol também procuram competir neste mercado. Mesmo com a história secular da cana no Brasil e com avanços já obtidos na curva de aprendizado do etanol, ameaças ao produto sempre existirão (uma que surge com mais profusão neste século é a do carro elétrico). Vale lembrar que, internacionalmente, o carro elétrico enfrenta menos restrições do que os carros movidos a etanol. Ou seja, o etanol não deve ser apresentado como uma escolha definitiva para substituir os derivados de petróleo. 
Em função disso, em termos de políticas públicas, tornam-se necessárias mais ações para intensificar a P\&D, estimular a melhoria da infraestrutura, logística e habilidades gerenciais necessárias para aprimorar os sistemas de produção do etanol. É importante destacar que a experiência brasileira pode pavimentar o caminho para o mercado internacional de etanol. Contudo, observam-se diversos grupos de interesse se opondo à expansão deste produto, cujos custos de produção ainda são elevados em outras partes do mundo. O etanol de segunda geração é apontado como a principal solução para essa limitação; porém, ainda não se mostra viável no atual estágio tecnológico.

Por fim, fica a recomendação para que mais pesquisas possam perscrutar a evolução do sistema do álcool combustível no Brasil, contribuindo para o debate acerca deste importante setor da economia brasileira.

\section{Referências bibliográficas}

ABRAMOVAY, R. A political-cultural approach to the biofuels market in Brazil. 2008. Disponível em: < http:// www.abramovay.pro.br/.>. Acesso em: 07/10/2011.

ALVEAL, C. O Brasil e os novos rumos da indústria mundial de petróleo. Revista Brasileira de Energia, Rio de Janeiro, v. 9, n. 1, p. 31-44, 2003.

ALVES, L. R. A. Transmissão de preços entre produtores do setor sucroalcooleiro do Estado de São Paulo. Piracicaba (SP), 2002. p. 107. Dissertação - Economia Aplicada, ESALQ/USP.

ARTHUR, B. Competing technologies, increasing returns and lock-in by historical events. The Economic Journal, Stanford University (CA), v. 99, n. 394, p. 116-131, mar. 1989.

ASSOCIAÇÃO DE PRODUTORES DE BIOENERGIA DO ESTADO DO PARANÁ (ALCOPAR). Produtos $e$ estatísticas. Disponível em: <http://www.alcopar.org. br>. Acesso em: 07/10/2011.

AVERBUG, M. Controvérsias em torno do etanol. Conjuntura Econômica, Rio de Janeiro, v. 61, n. 10, p. 25-27, Out. 2007.

BANCO NACIONAL DE DESENVOLVIMENTO ECONÔMICO E SOCIAL (BNDES); CENTRO DE
GESTÃO E ESTUDOS ESTRATÉGICOS (CGEE) (Orgs.). Bioetanol de cana-de-açúcar: energia para o desenvolvimento sustentável. Rio de Janeiro: BNDES, 2008. p. 316.

BELIK, W. Agroindústria processadora e política econômica. Campinas (SP), 1992. p. 219. Tese - Instituto de Economia, Universidade Estadual de Campinas.

BELIK, W., RAMOS, P. e VIAN, C. E. de F. Mudanças institucionais e seus impactos nas estratégias dos capitais do complexo agroindustrial canavieiro no Centro-Sul do Brasil. In: CONGRESSO NACIONAL DE ECONOMIA E SOCIOLOGIA RURAL, 36., PoçOs de Caldas, 1998. Anais... Poços de Caldas: SOBER, 1998.

BOUÇAS, C. Grandes empreendimentos que já nascem sustentáveis. Valor Econômico - Especial, São Paulo, p. 32-33, maio 2008.

CARDOSO, R. D., RODRIGUES, K. F., DAHMER, V. de S. e SHIKIDA, P. F. A. Índice de desenvolvimento do setor externo sucroalcooleiro brasileiro: uma análise de 1999 a 2007. Revista de Economia e Agronegócio, Viçosa (MG), v. 7, n. 3, p.337-361, Set./Dez. 2009.

CEZAR, G. Busca da eficiência une governo e empresários. Valor Econômico - Especial, São Paulo, p. 40-43, maio 2008.

CHIZZOTTI, A. Pesquisa qualitativa em Ciências Humanas e Sociais. Petrópolis: Vozes, 2006. p. 144.

CONCEIÇÃO, O. A. C. A dimensão institucional do processo de crescimento econômico: inovações e mudanças institucionais, rotinas e tecnologia social. Economia e Sociedade, Campinas, v. 17, n. 1 (32), p. 85-105, abr. 2008.

DAVID, P. Clio and the economics of QWERTY. American Economic Review Papers and Proceedings, Princeton, New Jersey, v. 75, n. 2, p. 332-337, may 1985.

ENDERLE, R. e GUERRERO, G. A. A herança patrimonialista na burocracia estatal do Brasil: path dependence patrimonialista e a falta da autonomia enraizada do estado brasileiro. In: ENCONTRO DE ECONOMIA DA REGIÃO SUL, 11., Curitiba, 2008. Anais... Curitiba: ANPEC Sul, 2008.

FERNANDES, E. S. L. e COELHO, S. T. (Orgs.) Perspectivas do álcool combustível no Brasil. São Paulo: USP - Instituto de Eletrotécnica e Energia, 1996. p. 166.

FORTES, G. Capital estrangeiro troca projetos por usinas já construídas. 2009. Disponível em: < http://www.udop. com.br/index.php?item $=$ noticias\&cod $=1060789>$. Acesso em: 07/10/2011.

GIL, A. C. Técnicas de pesquisa em economia. São Paulo: Atlas, p. 217. 2000. 
GOLDBERG, S. Na rota de Ásia e África, parcerias da Petrobras. Valor Econômico - Especial, São Paulo, p. 3739, maio 2008.

GONÇALVES JÚNIOR, C. A., ALVES, Y. B., SHIKIDA, P. F. A., STADUTO, J. A. R. e ROCHA JÚNIOR, W. F. da. Um estudo das deliberações da câmara setorial do açúcar e do álcool usando análise de correspondência. Revista de Economia e Sociologia Rural, Brasília, v. 47 n. 01. p. 183-210, Jan./Mar., 2009.

HODGSON, G. M. Economía institucional y evolutiva contemporánea. Cuajimalpa (México): Universidad Autónoma Metropolitana, 2007. p. 249.

JANK, M. S. Uma matriz de combustíveis para o Brasil. SOUZA, E. L. de e MACEDO, I. de C. (Coords.) Etanol e bioeletricidade: a cana-de-açúcar no futuro da matriz energética. São Paulo: Luc Projetos de Comunicação, 2010. p. 10-13.

LEVIN, K., CASHORE, B., BERNSTEIN, S. e AULD, G. Progressive incrementalism, and the "Super Wicked" problem of global climate change. In: CLIMATE CHANGE: GLOBAL RISKS, CHALLENGES AND DECISIONS CONGRESS, Copenhagen, Denmark, 2009. Disponível em: <http://environment.yale.edu/files/biblio/ YaleFES-00000143.pdf > . Acesso em: 22/09/2011.

MACEDO, I. C. Situação atual e perspectivas do etanol. Estudos Avançados, São Paulo, v. 21, n. 59, p. 157-165. 2007.

MORAES, M. A. F. D. de e SHIKIDA, P. F. A. (Orgs). Agroindústria canavieira no Brasil: evolução, desenvolvimento e desafios. São Paulo: Atlas, 2002. p. 368.

MOREIRA, R. R. e HERSCOVICI, A. Path-dependence, expectativas e regulação econômica elementos de análise a partir de uma perspectiva pós-keynesiana. Revista Economia Contemporânea, Rio de Janeiro, v. 10, n. 3, p. 547-574, set./dez. 2006.

NEVES, M. F. e CONEJERO, M. A. Sistema agroindustrial da cana: cenários e agenda estratégica. Revista de Economia Aplicada, Ribeirão Preto, v. 11, n. 4, p. 587-604, out./dez., 2007.

NORTH, D. C. Custos de transação, instituições e desempenho econômico. Rio de Janeiro: Instituto Liberal: 1994. p. 38. 1994.

NORTH, D. C. Institutions and the performance of economies over time. In: MÉNARD, C. e SHIRLEY, M. M. (Edts.). Handbook of New Institutional Economics. Springer: 2005. p. 21-30.

NORTH, D. C. Institutions, institutional change and economic performance. Cambridge: Cambridge University Press, 1990. p. 152.
PAULILLO, L. F., VIAN, C. E. de F. SHIKIDA, P. F. A. e MELLO, F. T. de Álcool combustível e biodiesel no Brasil: quo vadis? Revista de Economia e Sociologia Rural, Brasília, v. 45, n. 03. p. 531-565, jul./set., 2007.

PEROSA, B. B e AZEVEDO, P. F. de. Adoção de padrões socioambientais no mercado internacional de biocombustíveis. In: CONGRESSO NACIONAL DE ECONOMIA E SOCIOLOGIA RURAL, 49., Belo Horizonte. 2011. Anais... Belo Horizonte: SOBER. 2011.

PEROSA, B. B. Pesquisa por novos biocombustíveis: o que pode mudar para o Brasil? Revista Agroanalysis/FGV. Dezembro de 2010. p. 20-22.

PIRES, A. e SCHECHTMAN, R. Politicas internacionais de biocombustíveis. SOUZA, E. L. de e MACEDO, I. de C. (Coords.) Etanol e bioeletricidade: a cana-de-açúcar no futuro da matriz energética. São Paulo: Luc Projetos de Comunicação, 2010. p. 190-224.

PONDÉ, J. L., FAGUNDES, F. e POSSAS, M. Custos de transação e políticas de defesa da concorrência. Revista de Economia Contemporânea, Rio de Janeiro, n. 2, p.115135, jul./dez. 1997.

PONDÉ, J. L. Instituições e mudança institucional: uma abordagem schumpeteriana. Economia, Brasília (DF), v.6, n.1, p. 119-160, jan.jjul. 2005.

RAMOS, P. Agroindústria canavieira e propriedade fundiária no Brasil. São Paulo: HUCITEC, 1999. p. 243.

SACHS, R. C. C. Remuneração da tonelada de cana-deaçúcar no Estado de São Paulo. Informações Econômicas, São Paulo (SP), v.37, n.2, p. 55-66, fev. 2007.

SALDIVA, P. H. N., ANDRADE, M. de F., MIRAGLIA, S. G. El K. e ANDRÉ, P. A. de. O etanol e a saúde. SOUZA, E. L. de e MACEDO, I. de C. (Coords.) Etanol e bioeletricidade: a cana-de-açúcar no futuro da matriz energética. São Paulo: Luc Projetos de Comunicação, 2010. p. 98-135.

SHIKIDA, P. F. A. A evolução diferenciada da agroindústria canavieira no Brasil de 1975 a 1995. Piracicaba (SP), 1997. 191 p. Tese - Economia Aplicada, ESALQ/USP.

SHIKIDA, P. F. A., AZEVEDO, P. F. de e VIAN, C. E. de F. Desafios da agroindústria canavieira no Brasil pós-desregulamentação: uma análise das capacidades tecnológicas. Revista de Economia e Sociologia Rural (Impresso), v. 49, p. 599-628, 2011.

SIQUEIRA, D. A. e SIQUEIRA, A. A. Estudo e avaliação da tecnologia flex fuel. In: CONGRESSO NACIONAL DE ESTUDANTES DE ENGENHARIA MECÂNICA, 11., Nova Friburgo, 2004. Anais... Nova Friburgo: CREEM, 2004. 
SOUZA, E. L. de e MACEDO, I. de C. (Coords.) Etanol e bioeletricidade: a cana-de-açúcar no futuro da matriz energética. São Paulo: Luc Projetos de Comunicação, 2010. p. 314.

SOUZA, Z. J. de. Evolução e considerações sobre a cogeração de energia no setor sucroalcooleiro. In: MORAES, M. A. F. D. e SHIKIDA, P. F. A. (Orgs.). Agroindustria canavieira no Brasil: evolução, desenvolvimento e desafios. São Paulo: Atlas, 2002. Cap. 10, p. 214-240.

SZMRECSÁNYI, T. O planejamento da agroindústria canavieira do Brasil (1930-1975). São Paulo: HUCITEC/ UNICAMP, 1979. p. 540.

THE ECONOMIST. The post-alcohol world: the future of biofuels. Nov 2010, Volume: 397 Issue: 8706 pp.93-95.

THE ECONOMIST. The electrification of motoring. The electric-fuel-trade acid test. Sep. 3rd 2009. Disponível em: $<$ http://www.economist.com/displaystory.cfm?story_ id=14362092 > . Acesso em: 02/09/2011.

UNIÃO DA AGROINDÚSTRIA CANAVIEIRA DE SÃO PAULO (UNICA). Estatísticas e dados. Disponível em: <http://www.portalunica.com.br/portalunica/>. Acesso em: 09/09/2011.
UNICA. O setor sucroenergético: etanol, açúcar e bioeletricidade. São Paulo: UNICA, 2008. p. 12.

UNICA. Produção e uso do etanol combustível no Brasil: respostas às questões mais freqüentes. São Paulo: UNICA, 2007. p. 68.

VALENTIM, M. Tipos de pesquisa. 2008. Disponível em: $<$ http://www.valentim.pro.br/Slides/Metodologia/ Tipos_de_Pesquisa.ppt\#294,23,Slide 23>. Acesso em: 07/10/2011.

VEIGA FILHO, L. Energia sustentável dinamiza a economia. Valor Econômico - Especial, São Paulo, p. $8-13$, maio 2008 .

VIAN, C. E. de F. Agroindústria canavieira: estratégias competitivas e modernização. Campinas: Átomo, 2003. p. 216.

VÖLZ, H. E., PEREIRA, S. M. e SHIKIDA, P. F. A. Notas e considerações sobre o alcoolduto no Estado do Paraná. Revista Brasileira de Gestão e Desenvolvimento Regional, Taubaté, v.5, n.1, p. 95-120, jan./abr., 2009.

ZYSMAN, J. How institutions create historically rooted trajectories of growth. Industrial and Corporate Change, Oxford, UK, v. 3, n. 1, p. 243-283, 1994. 